\title{
ANALYSIS OF LEADERSHIP'S PRACTICES OF INDUSTRIAL ENTITIES
}

\author{
N. Sterev ${ }^{*}$ \\ Business Faculty, University of National and World Economy, Sofia, Bulgaria
}

\begin{abstract}
It could be said that the relation between leadership and industrial growth is ongoing and undoubted. Nevertheless, it has not been well studied yet, especially in Bulgaria.

Some basic reasons concern on the plurality of the definitions of "leadership" and "industrial growth" as different processes of the economic objects. Furthermore, to define as leadership phenomenon as well as industrial growth we need to settle the level of their foundations.

So, one of the suitable methods of understanding leadership and growth is to study them by the organizational behavior, resp. managerial practices.

According to the above, the paper is structured as follows: Introduction: the basic research thesis is given, 1. State of art: defining the problem. Summary of the most used definition of "leadership" and "industrial growth" are given in this paragraph. The connection between these two phenomena is also defined; 2.Analysis of managerial leadership's practices: some figures from the practice. Some basic endorsements of the managerial practices that are explained as leadership ones as well as practices that induce industrial growth are represented and discussed; Conclusions: summary of the knowledge of common business practices that help for business growing.
\end{abstract}

Key words: industrial growth, leadership, leadership practices, industrial business

\section{INTRODUCTION}

Bulgarian economy has been repaired too slowly from the 2008 s crisis. The industrial growth is still in the "future plans" of the Bulgarian Government even though the macroeconomic is stable. So, the macroeconomic policy could not possess enough potential to pull up the industrial growth.

There some explanations of the above situation: Bulgaria is the poorest EU-member state with the lowest figures of GDP per capita, or the 2008s was so deep that Bulgaria needs much more time to rebirth; or Bulgarian economy needs a restart to found a growth end etc.

Nevertheless, the industrial growth is creating inside the business entities from the real economy. So, for the growth decision should be percept one of the answers of the question: How to inspire an enterprise growth? An example of a "good" decision is: inspiration of leadership.

\footnotetext{
Correspondence to: Nikolay Sterev, Business Faculty, UNWE-Sofia, tel: +3592 8195 411,email: sterew@abv.bg
}

Some more prerequisites to the problem decision are given the next:

- $\quad$ For the inducing an industrial growth the priority is given to long-term development but not on short-term business stabilization measures;

- Industrial growth is prompt by industrial entities so the basic object of the paper are enterprises of Bulgarian manufacturing;

- Respectively, the macroeconomic stability is essential for the industrial growth, but it is not a priority object of the paper analysis;

- At last, but not least, a "good decisions" are those that ensure industry growth by increasing competitiveness of products. The mechanisms for establishing business competitiveness at micro and mezzo level are not an object of the paper.

The basic hypothesis of the paper is that the industry growth is accomplishing by inspiration of leadership in the business entities. So, leadership practises are set as a major point of the paper. In addition, leadership issues are very important element of the modern human resources management. Nevertheless, leadership problem is not 
discussed in the paper but it is based on widely accepted theoretical concepts and structures as "ready recipes and winged messages" for leadership and leaders in organizations.

There is no doubt that leadership matters and its application in business practice acquired particular stability of macroeconomic conditions as well as leadership is perceived as a major competitive factor.

\section{STATE OF ART}

There are some preliminary theoretical structures that we are needed to understand the basic problem "industrial growth - leadership".

\subsection{Growth dimension}

The theory of industrial growth is not the newest one, but the last 5-7 years have shown that we need a newer understanding of the growth phenomenon. So, it is an occasion to review the theories of economic growth, put at the core of modern economic science in the early XX century.

Theories of economic growth appear in the middle of XX century due to the expansion of markets in countries with "capitalist" form of management of the economy. Thus, the growth theories follow supplementing the general economic (political economy) theory basic mechanisms that underlie modern (for 1950s and 1960s) free market conditions.

Initially the theory of economic growth is used as a providing arguments or criticism of the existing status quo of economic neo-Classical, neo-Keynesians, monetarists and other economic flows (Stojanov 1992). In this phase of the adoption of the theory of growth most characteristic is that changing the position of the factors identified as a source of growth. So many internal company factors attributable to the policies and strategies of business organizations are defined as factors directly on the change of the growth of the entire economic system. According to the aforesaid, critics say the first economist Schumpeter pays particular attention to the internal variables of growth. Its growth theory is called "theory of evolution" because of the analogy with the development of other systems - biological, physical, etc.

The most significant theory is Schumpeter's one that presented a model of the turnover of the economic system (Figure 1), the growth of the economic system upsets the balance in the turnover and "drive" the system to take a new position.

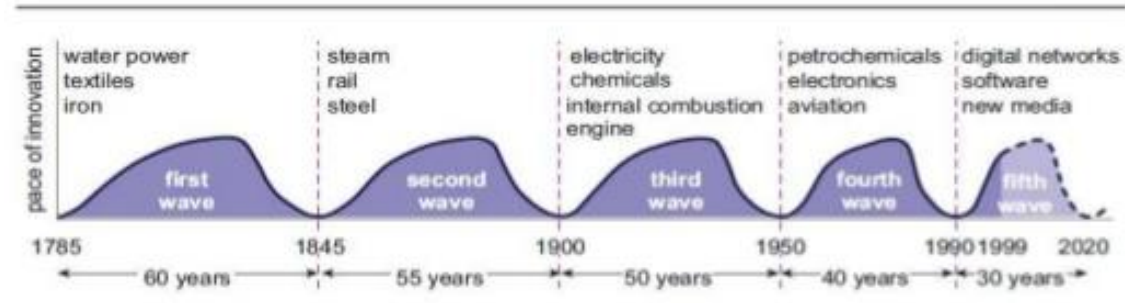

Figure 1 Schumpeter's waves accelerate

Source: adapted from The Economist (1999)

Figure 1. Model of the turnover of the economic system

Another important feature is the institutionalization of the developer - a leader, innovator, creator; which destroyed the traditional, creating new added value in society and promote the development of the economic system.

After Schumpeter's theory of growth is supplemented by such artists like Herbert Simon, Nelson and Winter, Demean and others. They utilized for a Schumpeterian entrepreneur economic system growth, develop terms and conditions of this growth. For example, Simon bind theory of growth with the theory of organizational behaviour and thus economic growth is the result of an economic rationality in companies. Thus, growth is not a result of search of optimal solutions and the adoption of satisfactory and acceptable ones. Nelson and Winter in turn extend the rational behaviour of Simon and put new figure, important for growth - namely, the creator of the new. According to them, the development of the organization of production and technology is a result of demand and creation of new knowledge.

In the modern theory of the growth plan developed by Eliasson, Carlson, Marleba and other European authors. Their theories, however, are directed more towards the study of the growth of various levels as studying microeconomic and macroeconomic growth and the relationship between them. Thus Eliasson concluded that the growth of an individual business is related to the 
sustainability of the development of the whole economic system. Moreover, the greater is the variation in companies, the more sustainable is the growth of the economy as a whole. The explanation is called "Brownian motion" of business within the economic system.

Using achieved by Eliasson dossier draws attention to demand diversity in the business of micro-level. So he offers a model for resolution of technical problems, according to its technological solutions is always less than possible technological variations. In the choice of technological solution does not depend on market demand and external to the existing economic system.

Theory of the growth in Bulgarian literature is presented inside the works of the authors as thefollows: Iv.Georgiev, D.Stoyanov, T.Nenov and B.Atanasov, D.Kopeva, N.Sterev and D.Blagoev and others. Development of theoretical and practical use of growth theories is leading in these publications. For example, D.Stoyanov emphasis on the restructuring of the economy and the impact of this change on growth, Iv.Georgiev focuses on mechanisms of organizational behaviour and choice of appropriate innovative projects and Kopeva, Sterev and Blagoev - the interaction between macroeconomic and microeconomic conditions for economic growth.

\subsection{Leadership dimension}

As a very important part of the modern Human resource management, leadership issues increasing fast of the researchers papers. And there is no doubt that leadership effects on the overall presentation of the business entities, including sells (at micro level) and GDP (at macro level).

As a leading point of view and understanding the leadership problems we percept the widely accepted theoretical structures of John Maxwell (2009) that are embodied in the works of J.Iliev, S.Koleva, D.Blagoev, K.Dimitrov and others:

- Leadership - it is quality of work while management - it is a job. The individual worker can that be appointed of a manager position, but it not means - a leadership position.

- Leadership represents actions with a focus on interpersonal relationships and achieving goals that followers perceive as their own goals.

- Leadership could be measured - neither more nor less.

- Leadership is the impact on people and $99 \%$ of it is performed not necessarily by the "top" and other people at various levels in the hierarchy of the business entities.

- Leadership is not necessarily superior position (cannot lead if I am not the "top"). It is a choice that is made, not "chair, which was standing."

- Leadership is process of creation of followers.

\section{3. "Growth-leadership" dimension}

When displaying the appropriate methodological tools of paper it is necessary to take a basic hypothesis:

- The relationship between "leadership" and "growth" is indisputable. The main problem of this relation is how to express and respectively, to measure (quantitative or quality) the both elements of relation.

According to the above, the studied relation should consider the following features:

- There are serious differences in the understanding of leaders and leadership as there are many definitions as results of the analysis of a particular situation.

- There are different theories about leadership, ways of its manifestation and creation. And here is a major problem the position of the analyser and the level represented the analysis. Moreover, theories of leadership are distinguished for national, sectorial or business level.

- There are specific features in the growth theories. Indisputable achievements of the authors of the 19th and 20th century, according to which growth is based on usage role of capital. It could not deny the theory of Schumpeter for role of management, innovation $и$ and entrepreneurship at achievement of the growth. But in latest years it is found that growth is not just economic issue, but also social and political dimension.

According to the above considerations suggest that the study of the relation "leadership" and "growth" is refracted through the prism of the behaviour of individuals. When using the above view that, in various models (stereotypes) of behaviour should be realized correlation between the different categories. At national level this phenomenon easy to identify, as far as the different regions is characterized by varying degrees of development, even with the imposition of a single model of leadership. At business level should conduct be investigated taking into account the following features:

- Social structure of the company, incl. relationships between roles in the company. We consider two basic premises:

- Built (incl. the existence of separate elements) of the system for human resource management (HRMS); 
- Practice of establishment (construction) and management teams;

- Corporate culture and values, incl. sustainable corporate belief, style of behaviour and the adoption of decisions. The problems of organizational culture could be reduced to the following issues:

- Culture based on the creation, maintenance and development of leaders, incl. building relationships "leader - followers".
STEREV N

- Culture based on key characteristics of psychology related to the acceptance / rejection of the community leaders.

- Culture based on personal motives, perceptions and attitudes of acceptance / rejection of models of leadership in business entities.

Taking into account the above considerations, the business level can be used the following model of relation "leadership - growth" (Figure 2).

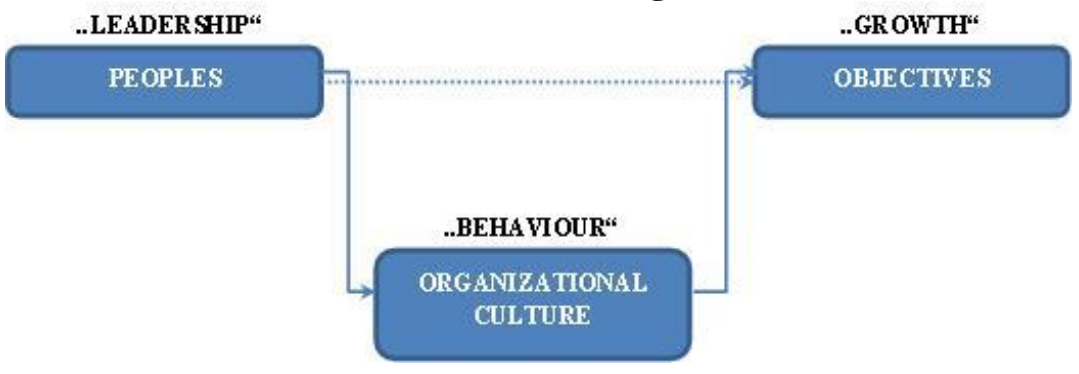

Figure 2. "Growth-leadership" model

This figure suggests deepening the methodological aspects of the theory of "managerial competence" and expansion of "leadership profiles" for different levels of government. Therefore, the main issues that must be resolved could be classified to the following:

- To set clear measurements for studying addiction: leading approaches in the management of the human factor - the management of the company. Main directions are:

- Competitiveness of the human factor;

- Indicators for the management of the contribution of the different levels of development of the company.

- Displaying understandable measures of the impact of management on the performance of the business' growth. Possible problems are:

- Minimizing the impact of the external environment and the concentration on the impact of domestic leadership on business growth;

$\circ$ Indicators for value added business and transfer this value potential for business growth;

- Indicators for leadership positions in the business of markets, for example through innovations in the market or sales management.

In the performance of above model leads to self-leadership to economic growth. Thus, the observed growth of business entities as a result of realizing the effect of management leadership is the result of previously implemented management decisions. All this suggests that the relation "leadership - growth" is not realized in a certain historical moment and is the result of long-term impact of the leader on growth factors.

However, another variable in the relation is needed: corporate capacity. The capacity does not allow to realize the full effect of the use of leadership and leaders to achieve growth of business organization. So, the capacity should take into account the relationship between: physical capital - social capital - human capital.

In design of the studied relation must be considered "middle path" and the deviation from it (Figure 3).

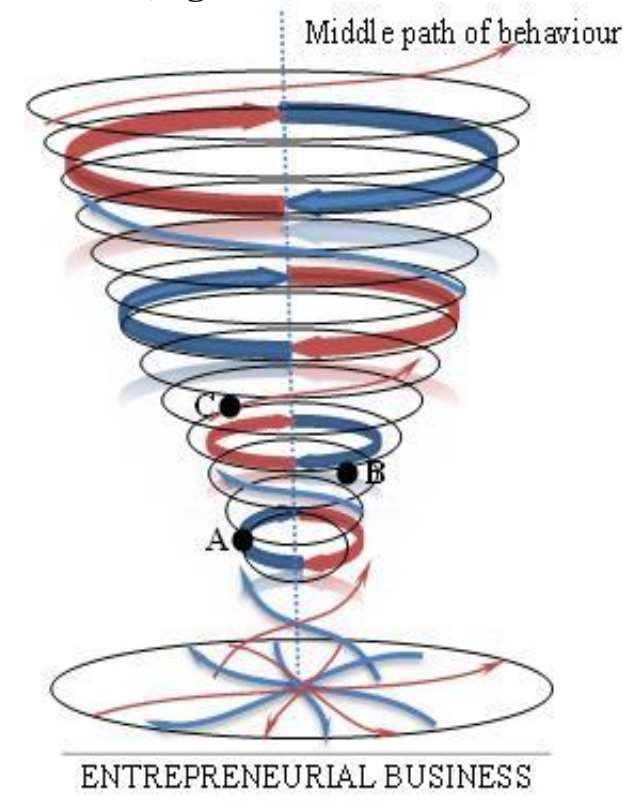

Figure 3. Model of business development through leadership 
It must take into account several problems as follows:

- Variations (resp. A, B, and C) are determined by differences in the internal rules of the different business entities (social structure).

- Growth was achieved in changing the model of leadership, not because of the qualities of the leader;

- The strongest effect was seen in autocratically management of corporate business.

\section{ANALYSIS OF MANAGERIAL LEADERSHIP'S PRACTICES}

The analysis is based on survey of industrial entities that is done by project NID NI 1 5/2013 financed by Scientific Research Fund of UNWE. As a project task, there is done primary verification and validation of information collected from 83 observations. All analysed 83 observations covering small, medium and large industrial entities in various subsectors and product specialization within the manufacturing, as well as covering industrial companies from different geographical areas of the country. Choosing the observed industrial entities is random, but the structure of observed companies is not adequate neither the product nor the geographical structure of the industrial business in the country. However, it can be assumed that the observed industrial enterprises provide a clear picture of leadership potential and growth opportunities for industrial business in Bulgaria.

The main demographic characteristics of the observed 83 industrial entities are presented in Table 1.

Table 1. Major demographic characteristics

\begin{tabular}{|l|r|r|r|r|r|r|}
\hline & $\begin{array}{c}\text { Production } \\
\text { (thousand } \\
\text { BGN) }\end{array}$ & $\begin{array}{c}\text { Labour } \\
\text { costs } \\
\text { (thousand } \\
\text { BGN) }\end{array}$ & $\begin{array}{c}\text { Value of } \\
\text { fixed } \\
\text { assets } \\
\text { (thousand } \\
\text { BGN) }\end{array}$ & $\begin{array}{c}\text { Revenues } \\
\text { from sales } \\
\text { (thousand } \\
\text { BGN) }\end{array}$ & $\begin{array}{c}\text { Financial } \\
\text { result } \\
\text { (BGN) }\end{array}$ & $\begin{array}{c}\text { Number } \\
\text { of } \\
\text { employees }\end{array}$ \\
\hline Average & 76,237 & 3306 & 11,127 & 78,471 & 1782 & 313 \\
\hline
\end{tabular}

Source: Data from project and own calculations using SPSS (19.0 v).

An analysis of leadership practices required to systematize what is being done and what - not in the establishing of leaders in business entities (Figure 4).

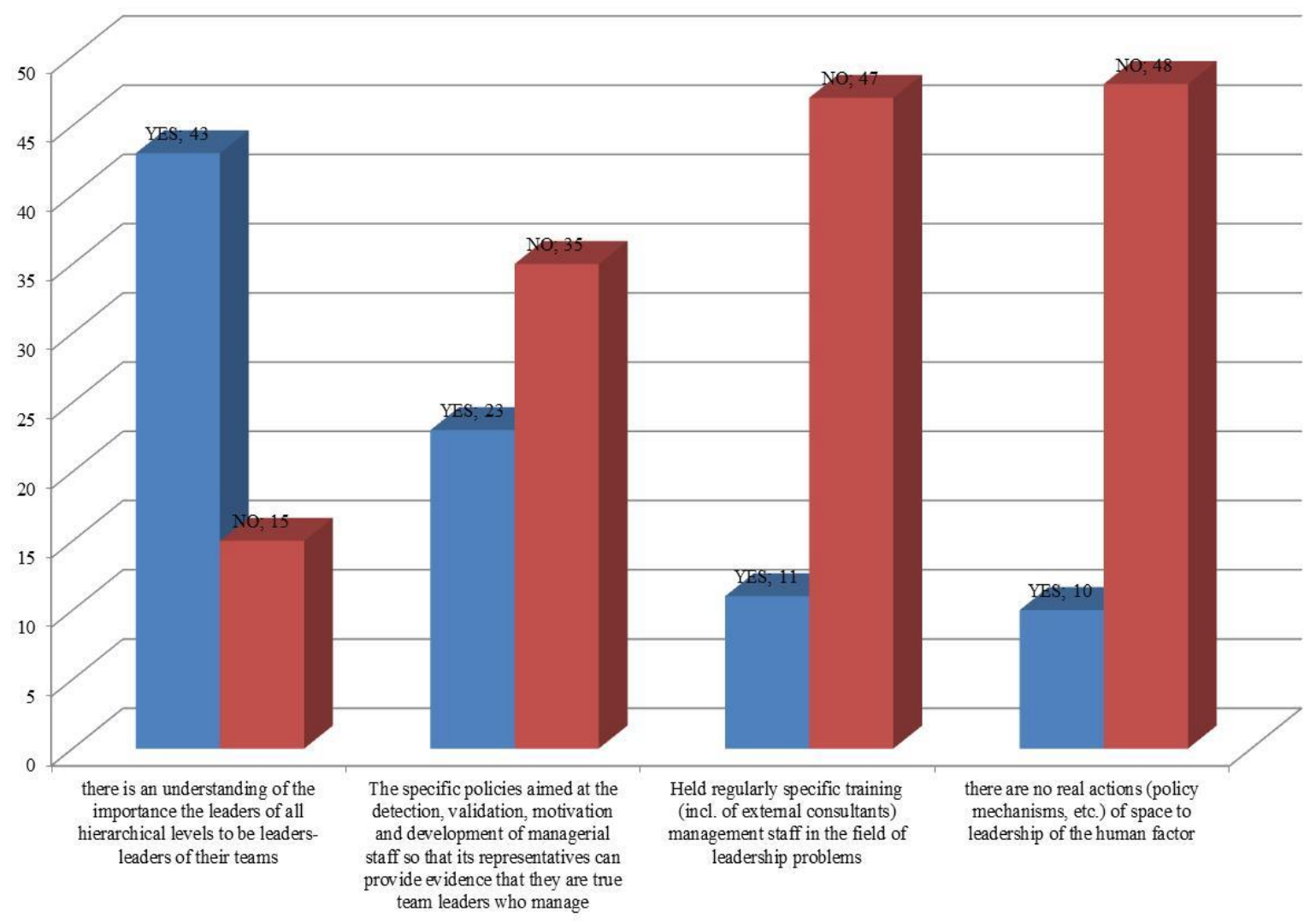

Source: Data from project and own calculations using SPSS (19.0 v).

Figure 4. Graphical representation of the distribution of responses in terms of leadership in its human dimensions (resp. Leadership of the human factor), in organization 
The data obtained show that only one of every five firms (17.2\%) no action in the area giving space to the leadership of the human factor. At the same time you $3 / 4$ of managers $(74.1 \%)$ there is a good enough understanding of the importance of leaders at all hierarchical levels of management.

Despite the above, not large proportion of the industrial entities actually take action to detect and validation of leaders - only $39.07 \%$. Even lower share of industrial organizations develop their leaders through regular and specific training $-19 \%$.

The second problem is on the perception of the leader of the organization and its inherent power tools. An important test of the skills of managers- leaders is how exercise its administrative power management (Figure 5).

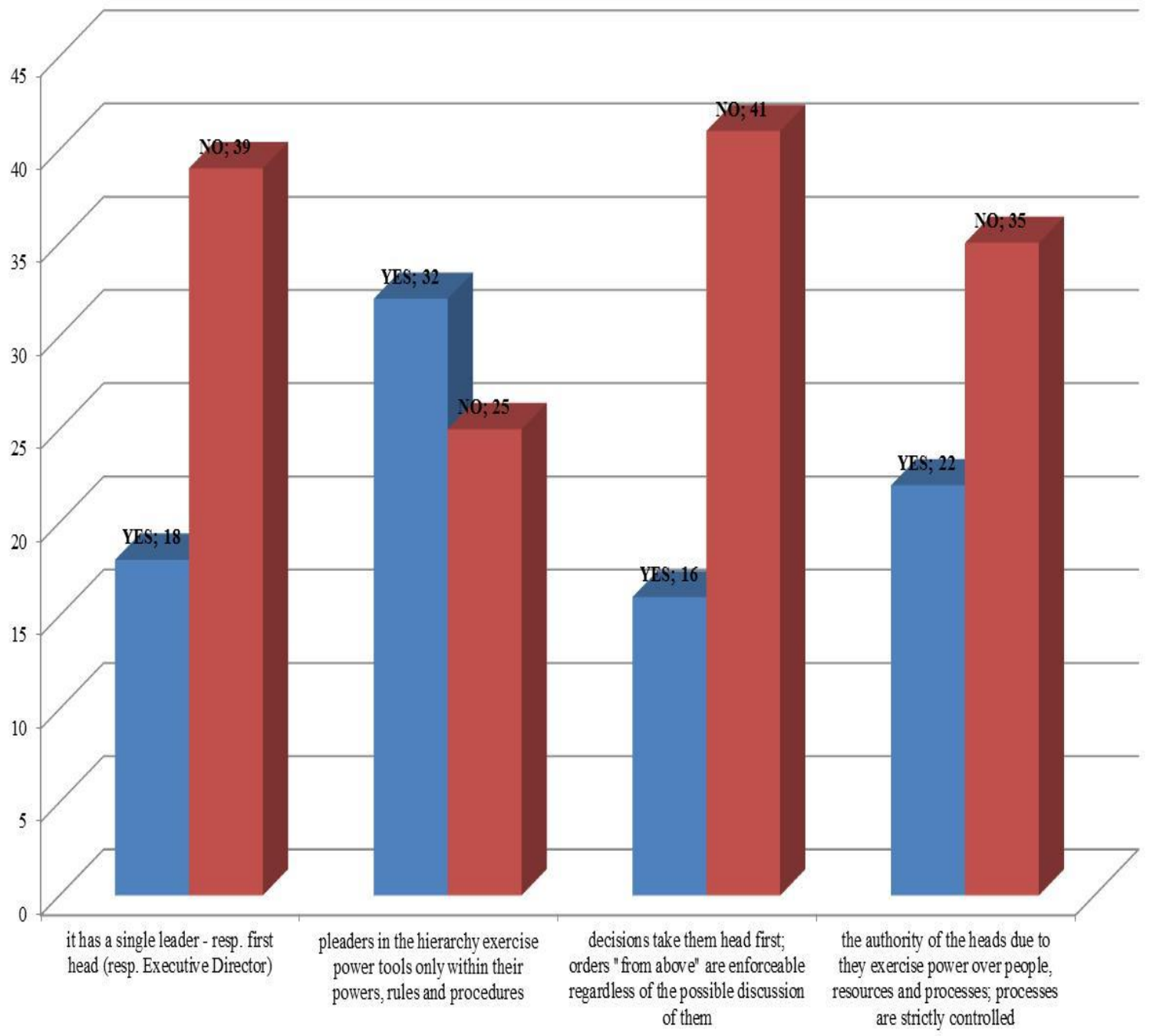

Source: Data from monitoring and own calculations using SPSS (19.0 v).

Figure 5. Graphical representation of the distribution of responses in terms of understanding the leadership of the human factor in the organization

The data obtained show that in the majority of monitored companies (perhaps due to their size) has the power dissipation and distribution of power tools between leaders. The positive here is that $56 \%$ of respondents' power tools are exercised according to the rules and procedures within the powers of the managers. In addition to the above, only about $1 / 3^{\text {rd }}$ of the companies there is only one leader - the first head and an even smaller part of them (28.1\%) did not allow for discussion on their management arrangements.
Another positive point is that three out of five companies $(61.4 \%)$ the authority of the leader is not due to its exclusive right to allocate resources and activities. However, it is disturbing fact that $40 \%$ of respondents' leader took advantage of their right to manage resources and processes to build your credibility.

The third problem relates to practices opposing the consolidation of leadership in business organizations (Figure 6 - left). 

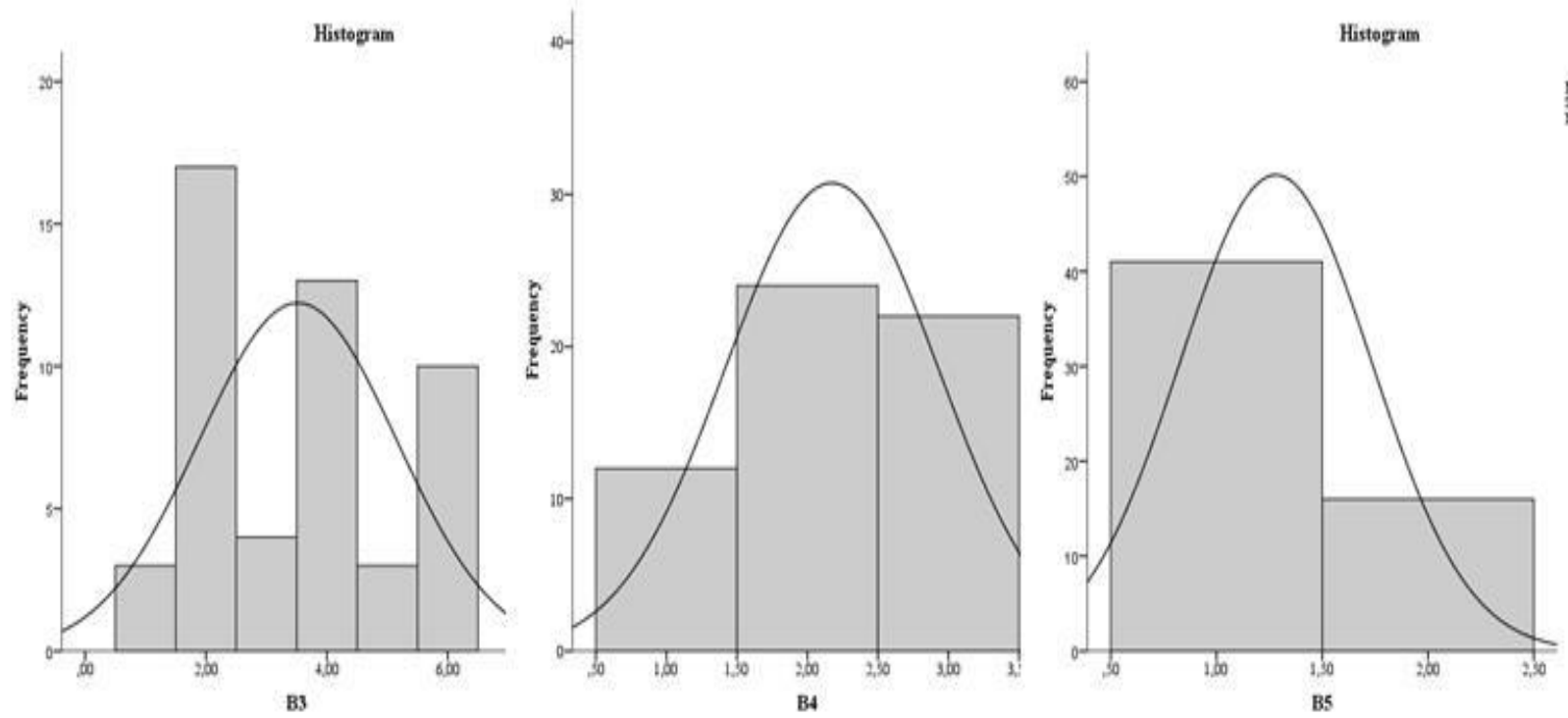

Source: Data from project and own calculations using SPSS (19.0 v).

Figure 6. The graphical representation of the distribution of the answers to the practices of the leadership opposing the human factor (left), management style (centre) and of personal commitment of the Managing Head (right) in the industrial business

The data obtained show that most part (about 4 of every 5 companies) $80 \%$ of the observed companies practices on opposing the leadership of the human factor, based on the principles of the established power:

- There are well-established attitudes and behaviour in leaders to implement what they are told the "top" of 34\%;

- There is acceptance without proof that every manager is also the leader of the team that manages about $26 \%$;

- There is channelled system for managing human resources in the organization, and formulated teams $20 \%$.

Negligible are the companies for which knowledge of leadership issues are considered to be an insurmountable obstacle for the leadership of the human factor:

- There is a lack of knowledge about leadership and leaders in an organization - 6\%;

- There is a perception of the leader as a threatening power and control of senior management $-6 \%$.

The fourth problem is the management style used in practice (Figure 6 - centre). The data obtained show a positive phenomenon: 4 out of 5 companies. So, $80 \%$ of the observed companies, their managers use democratic or liberal style of management and the distribution is as follows:

- democratic management style of his subordinates used by $41.4 \%$ of the managers;

- liberal management style of his subordinates used by $37.9 \%$ of the managers;

- authoritarian style of his subordinates is the practice of $20.7 \%$ of the managers.
The fifth problem is the focus of attention of the head (Figure 6 - right). The data obtained clearly show that $3 / 4^{\text {th }}$ of managers focus on the obligations and terms for performance of tasks and just over $25 \%$ indicate their personal attachment to the individuals in the organization.

- orientation obligations, tasks, deadlines for the implementation (of the team) - for $71.9 \%$;

- $\quad$ orientation to the people (staff members), relationships, interaction, interpersonal relationships within the team - to 28.1 percent.

\section{CONCLUSIONS}

Data analysis allows highlighting two areas:

- $\quad$ First, use of counteracting practices depends from understanding for leadership and funds for building of authority of Head. In this with found understanding of importance of leader and availability of actual practices and at strict control of processes it is there use of order "from above" as tool for counteraction of leader. Conversely, in the absence of failure of understanding of leader's absence of real actions for validation of leadership and absence of strict control it is ignorance: ignorance for leadership problems or absence of system for management of human resources.

- Second, focus of Head. When authority of Head to duties of control over resources and processes - orientation is to responsibilities, tasks, deadlines for performance. Conversely, when the authority of Head not to duties of control on resources and processes - orientation of management is placed to people (members of team), 
relationships, interaction, interpersonal relations in team

In summary, the analysis of perceptions and attitudes towards leadership problems and ways of their realization in practice of industrial companies outlines two basic types of managers:

1. First group of managers who know the benefits of leadership of the human factor, distributed power between different hierarchical levels and rely on interpersonal relationships established with liberal management style.

2. Second group leaders who are considered the only leader not tolerate the use of democratic tools and rely on the possession of weapons administrative power in their relations with their subordinates.

3.

Finally, what helps to industrial business to growth?

According to the above results and theoretical background the growth of the industrial entities is achieved by activities such as follows:

- $\quad$ conduct regular staff training;

- power distribution according to the powers and limit the authority of a single leader;

- $\quad$ limiting the behaviour of managers to "perform what they are told the" top ".

In addition, proposed actions had to cover at least the next 5 individual possessed leadership qualities that are extremely high important for the industrial growth:

- Responsibility and determination;

- $\quad$ Ability to motivate;

- Confidence.

- Wits;

- Maturity.

\section{REFERENCES}

1. Georgiev I. et al, Enterprise economics, UP Stopanstvo, 2009 (BG)

2. Georgiev I., Growth of the enterprise, UP Stopanstvo, 2001(BG)

3. Iliev J, D.Blagoev et al., Leadership and industrial growth in Bulgaria, PC UNWE, 2015 (BG)

4. Iliev J., Management by motivation, VFUVarna, 2009 (BG)
5. Maxwell J., 360-degree leader, East-West, 2010 (BG)

6. Maxwell J., Build leaders around him, New man, 2008 (BG)

7. Stoyanov D., Industrial growth, UP Stopanstvo, 1993 (BG)

8. Blagoev, Sterev, Kopeva, Industrial growth investment behavior and innovation in Bulgaria, Journal of Regional and Business Studies, Vol. No1 (2011), Kaposvar, Hungary, pp. 683-697

9. Bresnahan and F.Malerba, 1997, Industrial dynamics and the evolution of firms and nations competitive capabilities in the world computer industry, paper;

10.Carlsson, B., Eliasson, G. (2001), "Industrial dynamics and endogenous growth", paper prepared for the Nelson and Winter Conference of the Danish Research Unit for Industrial Dynamics (DRUID), June, available at: www.druid.dk/conferences/nw/

11.Dosi G. and F.Malerba, 2003: "Special Issue on Industrial Dynamics",Industrial and Corporate Change, 11, 619-633.

12.Eliasson, G.,1998. "Competence Blocs and Industrial Policy in the Knowledge Based Economy". OECD Science, Technology, Industrial (STI) Revue;

13.Jones B.F. and B.A.Olken, Forthcoming, DO LEADERS MATTER? NATIONAL LEADERSHIP AND GROWTH SINCE WORLD WAR II, Quarterly Journal of Economics, February 2005

14.Lawler, E., From job-based to competencybased organizations, Journal of Organisational Behaviour, 15, 1994.

15.McClelland, D., Where do we stand on assessing competencies?, National Conference on Competency-based Tools and Applications, Chicago, November, 1994.

16.Vroom V., and P.Yetton, Leadership and decision-making, University of Pittsburg Press, 1973

17.Winter S., Y.Kaniovski, G.Dosi, 1998, Modeling Industrial Dynamics with Innovative Entrants, International Institute for Applied Systems Analysis, IR-98-033 /May 1998. 
